\title{
Explore the radiotherapeutic clinical target volume delineation for small cell lung cancer with lower cervical lymph node metastasis according to CT- images.
}

\author{
Ting Gao ${ }^{1 \#}$, Xiaopeng $\mathrm{He}^{1 \#}$, Yan Dang ${ }^{1 *}$, Yindi Jiang ${ }^{2}$, Youwen Yang ${ }^{3}$, Yujuan $\mathrm{Ma}^{1}$, Min $\mathrm{Li}^{4}$, Shuli \\ Yuan $^{1}$, Jianhui Chen ${ }^{1}$ \\ ${ }^{1}$ Department of Respiratory Medicine, Xianyang Center Hospital, Xianyang, Shanxi province, PR China \\ ${ }^{2}$ Hematology Department, Xianyang Center Hospital, Xianyang, Shanxi province, PR China \\ ${ }^{3}$ Department of Radiation Oncology, Xianyang Center Hospital, Xianyang, Shanxi province, PR China \\ ${ }^{4}$ Department of Radiology, Xianyang Center Hospital, Xianyang, Shanxi province, PR China \\ \#These authors contributed equally to this work
}

\begin{abstract}
Background: In limited stage small cell lung cancer, involved field irradiation has been considered as standard. However, there have recent reports suggesting higher than expected nodal recurrence in the supraclavicular region. The study aimed to explore the reasonable radiotherapy range of supraclavicular zone for patients receiving prophylactic or radical radiation.

Patients and methods: Supraclavicular zone was further divided into 4 zones, including upper pararecurrent laryngeal neural region (UP region), lower para-recurrent laryngeal neural region (LP region), medial supraclavicular region (MS region), and lateral supraclavicular region (LS region). And we analysed the distribution of lymph node metastasis in supraclavicular zone based on CT-images.

Results: our data showed that metastases occurred most frequently in the medial supraclavicular region

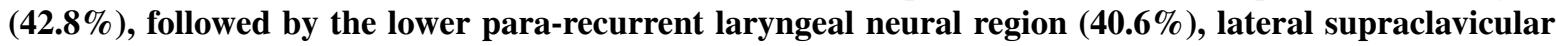
region $(9.4 \%)$, and upper para-recurrent laryngeal neural region $(7.2 \%)$, respectively.

Conclusion: If prophylactic irradiation therapy is considered, the target zones for prophylactic irradiation should include MS region and LP region as recommended.
\end{abstract}

Keywords: Small cell lung cancer, Radiotherapy, Clinical target volume, Supraclavicular lymph node.

Accepted on January 29, 2018

\section{Introduction}

Small Cell Lung Cancer (SCLC) remains a major public health problem and accounts for $10 \%$ to $15 \%$ of all lung cancers [1] It has unique clinical features such as rapid growth, early metastatic spread, and widespread dissemination. At present, definitive chemoradiation is considered a standard treatment option for limited disease SCL (LD-SCLC). As a component of this therapy, radiotherapy is an important integral part of the management of LS-SCLC, which promotes local control and also contributes to the survival benefit for patients with limited disease [2]. Historically, radiotherapy portal included all mediastinal Lymph Nodes (LNs) and supraclavicular LNs irrespective of primary tumor extent [3-6]. Due to the chemotherapy and incidental radiation therapy to subclinical disease in the uninvolved lymph nodes might have been sufficient, isolated out-field nodal recurrences are seldom seen. Hence, it is common to see omission of elective nodal irradiation applied in clinical practice [7-11].
However, several clinical studies demonstrated that the involved field radiotherapy (IFRT) by Computed Tomography (CT) scans or Positron Emission Tomography (PET-CT) in patients with LS-SCLC resulted in a higher than expected rate of lymph nodal failures in the supraclavicular region, in particular for patients with N2/N3 status [9,11-15]. Although we applied IFRT for those patients, actually, incidental irradiation has been delivered to the surrounding areas, especially mediastinal regions [16]. Hence, the lymph nodal failures in the mediastinal station are extremely rare. However, supraclavicular region seldom received incidental radiation therapy, which exposed this region to a relatively high risk of outfield failure, as was seen in those studies [9,11-15]. In the current era of precise radiotherapy, the clinical target volume for radiotherapy is mainly confirmed by CT-images means. The target area for the mediastinum region and the lower abdominal region is relatively clear, while supraclavicular region is not. 
In the current study, we performed a retrospective analysis to investigate the regularity of spontaneous metastasis to lower cervical lymph nodes in 93 SCLC patients, to explore the pattern and to find out the high-risk regions of lower cervical Lymph Node Metastasis (LNM). Finally, we hope to provide an information concerning the CTV of lower cervical for SCLC patients.

\section{Methods and Materials}

\section{Patients}

After obtaining the approval of the institution's research ethics board, we performed a single-center retrospective analysis of 453 patients with diagnosed SCLC during 2010 through 2014. Stage of disease was determined using brain Magnetic Resonance Imaging (MRI), contrast-enhanced CT of the cervical, chest and abdomen, bone scintigraphy, and PET-CT was also used for some patients. The inclusion criteria were as follows: (1) patients with supraclavicular LNM; (2) there have lower neck CT scan. The exclusion criteria were mixed pathology between non-small and small cell cancer, before or coexisting malignancies.

\section{Definition of lower cervical regions}

Currently, there is no uniform standard to partition the supraclavicular region. On the basis of some studies, we classified the lower neck into the two sides, the midline of the body serves as the border between right and left [16-18]. Moreover, each region was classified into 4 groups as upper para-recurrent laryngeal neural region (UP region), lower pararecurrent laryngeal neural region (LP region), medial supraclavicular region (MS region), lateral supraclavicular region (LS region). Table 1 showed the details of the anatomic structures for each region. Figure 1 showed the sketch map of each region at different bedding planes of CT-image.

\section{Diagnostic criteria for $L N M$}

(1) A single LN with a short axis $>10 \mathrm{~mm}$, or a single $\mathrm{LN}$ with a short axis $<10 \mathrm{~mm}$ combined with hoarseness or vocal cord paralysis, or there are more than three LNs in the same mediastinal region on enhanced CT-images.

(2) The presence of necrosis, markedly inhomogeneous enhancement on enhanced CT scans; positive LNs appeared at uncommon regions; fluorodeoxyglucose-avid (if used); and the response to anti-tumor therapy was obvious [19-21]. All images were reviewed and interpreted by 2 experienced radiological experts.

\section{Lymph node depicting}

The positions of the metastatic lower cervical LNs for all enrolled patients were re-read respectively and then recorded the positions of positive LNs based on previous literature $[21,22]$.

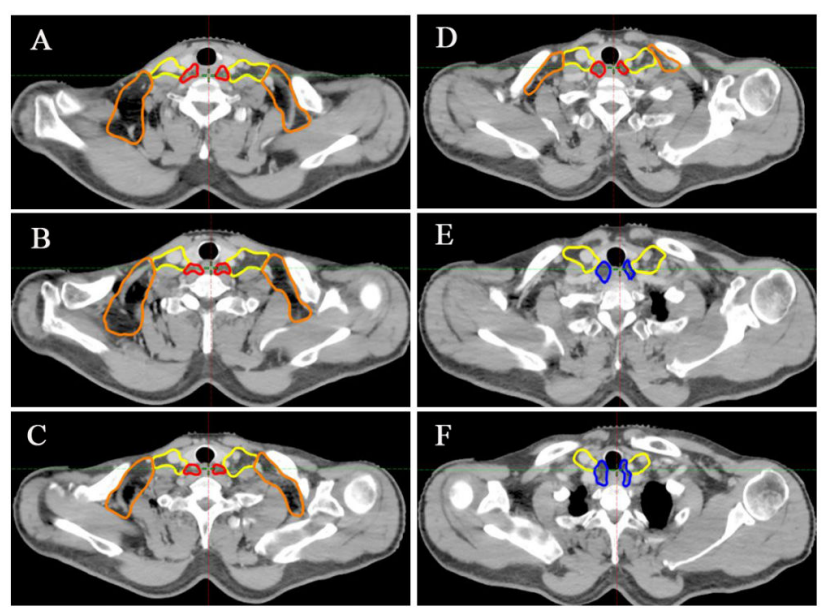

Figure 1. Schematic diagrams of zoning at different bedding planes of CT-imaging in lymphatic drainage area. Regions encircled with red line are UP region, with blue line are LP region, with yellow line are $M S$ region, and with orange line are $L S$ region.

\section{Results}

\section{Patient characteristics}

After the inclusion and exclusion criteria, 93 patients were included in this study. Clinical Features of Patients with SCLC and the characteristics of tumor are summarized in Table 2. The median age of those patients included in this study was 57 years (range, 48-74 y). Of these 93 patients, 67 patients were male and 26 female. Of the 93 patients whose records were examined, a total of 138 metastatic LNs were found in the lower cervical region, and the number of positive LNs per patient ranged from 1-3. Among all 138 nodes, 47.1\% located on the left and $52.9 \%$ located on the right.

\section{Patterns of metastatic lymph node distribution}

The frequencies of metastatic lymph nodes in each region are listed in Table 3. Overall, lymph nodes metastases occurred most frequently in the medial supraclavicular region $(42.8 \%)$, followed by the lower para-recurrent laryngeal neural region $(40.6 \%)$, lateral supraclavicular region $(9.4 \%)$, and upper pararecurrent laryngeal neural region $(7.2 \%)$, respectively.

Table 1. The bound marks for CT image-based zoning of supraclavicular lymph nodes of patient with small cell lung cancer.

\begin{tabular}{ll}
\hline Zone & Boundary \\
\hline Upper para-recurrent laryngeal neural region (UP region) & Upper border: lower margin of the cricoid cartilage \\
\cline { 2 - 2 } & Lower border: apex of the right lung and pleural space \\
\hline
\end{tabular}


Explore the radiotherapeutic clinical target volume delineation for small cell lung cancer with lower cervical lymph node metastasis according to CT-images

\begin{tabular}{|c|c|}
\hline & \multirow{2}{*}{ Anterior border: anterior border of the carotid artery; posterior border of the trachea } \\
\hline & \\
\hline & Posterior border: anterior border of the vertebral body \\
\hline & Lateral border: The inside of the internal carotid artery \\
\hline \multirow[t]{5}{*}{ Lower para-recurrent laryngeal neural region (LP region) } & Upper border: apex of the right lung and pleural space \\
\hline & Lower border: upper border of the manubrium \\
\hline & Anterior border: anterior border of the carotid artery; posterior border of the trachea \\
\hline & Posterior border: anterior border of the vertebral body \\
\hline & Lateral border: the inside of the internal carotid artery \\
\hline \multirow[t]{6}{*}{ medial supraclavicular region (MS region) } & Upper border: lower margin of the cricoid cartilage \\
\hline & $\begin{array}{l}\text { Lower border: outer edge of junction of internal jugular and subclavian vein, the lower edge of the external } \\
\text { jugular vein }\end{array}$ \\
\hline & Anterior border: dorsal side of sternocleidomastoid muscle \\
\hline & Posterior border: front edge of the anterior scalene muscle \\
\hline & $\begin{array}{l}\text { Lateral border: ligature from the rear edge of sternocleidomastoid muscle to outer edge of anterior } \\
\text { scalenus muscle }\end{array}$ \\
\hline & Medial border: medial border of the carotid artery \\
\hline \multirow[t]{6}{*}{ Lateral supraclavicular region (LS region) } & Upper border: outer bound of supraomohyoid muscle \\
\hline & Lower border: lower edge of external jugular vein \\
\hline & Anterior border: clavicle/skin \\
\hline & Posterior border: ventral side of supraomohyoid/levator scapula/medial scalene \\
\hline & Lateral border: ribs or trapezius \\
\hline & $\begin{array}{l}\text { Medial border: ligature from the rear edge of sternocleidomastoid muscle to outer edge of anterior } \\
\text { scalenus muscle }\end{array}$ \\
\hline
\end{tabular}

Table 2. Clinical characteristics of 45 small cell lung cancer patients with SCV node involvement and the distribution of those nodes.

\begin{tabular}{ll}
\hline Characteristic & No. of patients or nodes \\
\hline Age $(\mathrm{y})$ & 57 \\
\hline Median & $48-74$ \\
\hline Range & \\
\hline Sex & 67 \\
\hline Male & 26 \\
\hline Female & \\
\hline Tumor location & 23 \\
\hline Right upper lobe & 26 \\
\hline Right middle/lower lobe & 21 \\
\hline Left upper lobe & 23 \\
\hline Left lower lobe & 23 \\
\hline The number of SCV LNM & 138 nodes \\
\hline
\end{tabular}

Abbreviation: SCV: Supraclavicular; LNM: Lymph Node Metastases. Data presented as $\mathrm{n}(\%)$, unless otherwise noted.

Table 3. Analysis of lymph node metastasis to cervical zones.

\begin{tabular}{ll}
\hline Region & Number of nodes \\
\hline UP region & 10 nodes $(7.2 \%)$ \\
\hline LP region & 56 nodes $(40.6 \%)$ \\
\hline MS region & 59 nodes $(42.8 \%)$ \\
\hline LS region & 13 nodes $(9.4 \%)$ \\
\hline $\begin{array}{l}\text { Abbreviation: UP region: Upper Para-recurrent laryngeal neural region; LP } \\
\text { region: Lower Para-recurrent laryngeal neural region; MS region: Medial } \\
\text { Supraclavicular region; LS region: Lateral Supraclavicular region }\end{array}$
\end{tabular}

\section{Determination of radiotherapeutic target zones for $S C L C$}

According to our study, most lymph node metastasis sites are located in the MS region and LP region $(83.3 \%, 115$ of 138 nodes). These two regions are high risk areas for lymph node metastasis. Therefore, if consider prophylactic radiation to the lower neck, only the MS region and LP region need to be included in Clinical Target Volume (CTV). 


\section{Discussion}

Omission of uninvolved nodal stations in radiation therapy is a straightforward strategy to reduce the radiation related toxicity, as has been recently reported $[7,9,12,13,23]$. However, the use of involved-field radiotherapy (IFRT) or Elective Node Irradiation (ENI) in LS-SCLC remains controversial [24]. Although IFRT is becoming common in contemporary clinical practice, high-level evidence to support the practice of omission of ENI is still rare. Recently, several clinical studies reported that a high incidence of local nodal failure, were noted in supraclavicular fossa in patients of LS-SCLC. Tada et al. [25] examined the pattern of failures in patients with SCLC treated with IFRT. The results showed that patients with N2 or N3 LS-SCLC appeared to have more regional relapses in the upper mediastinum and supraclavicular fossa. Similarly, De et al. [12] demonstrated that the IFRT on the basis of CT scans in patients with SCLC resulted in a higher than expected rate of isolated nodal failures in the supraclavicular fossa. Recently, a prospective study conducted by $\mathrm{Hu}$ et al. [11] reported patterns of recurrence after IFRT in LS-SCLC. In their study, isolated nodal recurrences, which all in the ipsilateral supraclavicular fossa, were reported with mediastinal N3 disease in $100 \%$ patients. Therefore, based on their preliminary results, in one of his studies, N3 disease patients will receive prophylactic irradiation to the ipsilateral lower neck. Accurately delineating the scope of irradiation range is the prerequisite for treatment. However, accurate determination of the appropriate range of radiation is challenging for clinical practice.

At presents, there is still no relevant recommendation for radiotherapy in supraclavicular lymph node zone of small cell lung cancer. Target volumes are often defined primarily on the basis of the distribution of normal lymphatics or by vascular and bony landmarks. A large lateral extent of the irradiation field theoretically brings a greater regional control. However, the more generous coverage discussed herein must be balanced by an awareness of potential toxicities associated with treatment. Extensive research indicated that a large lateral extent of the lower neck irradiation field could bring more toxicity by irradiating extra volumes, especially lymphedema, lung damage, and brachial plexopathy. A study performed by Graham et al. investigated the effect of Supraclavicular Fossa (SCF) radiotherapy volumes on the development of lymphoedema. The results showed that irradiation field lateral to the coracoid process was a significant risk factor for lymphedema $(\mathrm{P}=0.002)$ [26]. In the MA.20 trial, the irradiation field included the head of clavicle medially and the coracoid process laterally and the levels I and II axilla in some patients. The results showed that those patients had higher rates of lymphedema $(8.4 \%$ vs. $4.5 \% ; \mathrm{P}=0.001)$ and acute pneumonitis ( $1.2 \%$ vs. $0.2 \% ; \mathrm{P}=0.01)$ [27]. Those dates indicated that irradiating extra volumes would be associated with more toxicity. Hence, it is important to accurately define the supraclavicular nodal region at risk, which could better cover target areas and spare normal tissues. The central aim of this study was to characterize the distribution of these nodes according to CT scan in patients with supraclavicular regional lymph node involvement and to use this evidence to suggest contours of the reasonable CTV margin in the supraclavicular zone. Recently, Luo et al. [28] explored the distribution pattern of lower cervical metastatic lymph node in esophageal cancer and found that supraclavicular zone metastasis frequently occurred in the cervical paraesophageal lymph nodes and lower cervical fossa. Inconsistent with the study of EC. As shown in Table 3, metastasis frequently occurred in MS region and the LP region for SCLC patients. While the incidence in others region is low, it may be reasonable to exclude these lymph nodes from the CTVn. Based on this study, the MS region and LP region are considered to be the high risk regions for LNM, which were the regions for prophylactic irradiation.

There are some limitations in this study. Firstly, it was a retrospective study, our data originated from a single institution and the sample size of the present study was not enough. Furthermore, the diagnosis of positive LNs in the present study was on the basis of image data, rather than pathological evidence. Thus, we cannot make sure that all of the enlarged lymph nodes contain metastatic lesions. Fortunately, Most of the patients with lower cervical metastases in the study were underwent the PET/CT image, and PET/CT is generally reported to have a high rate of sensitivity and specificity in this setting $[13,29,30]$. Thus, the outcome of our study is credible.

\section{Conclusion}

In a word, the study we conducted was aimed to provide a reference for the supraclavicular region target delineation of SCLC. If prophylactic irradiation therapy is considered, the target zones for prophylactic irradiation should include MS region and LP region as recommended.

\section{Disclosure}

None

\section{References}

1. Govindan R, Page N, Morgensztern D, Read W, Tierney R, Vlahiotis A. Changing epidemiology of small-cell lung cancer in the United States over the last 30 years: analysis of the surveillance, epidemiologic, and end results database. J Clin Oncol 2006; 24: 4539-4544.

2. Lally BE, Urbanic JJ, Blackstock AW, Miller AA, Perry MC. Small cell lung cancer: have we made any progress over the last 25 years? Oncologist 2007; 12: 1096-1104.

3. Perry MC, Eaton WL, Propert KJ, Ware JH, Zimmer B, Chahinian AP, Skarin A, Carey RW, Kreisman H, Faulkner C. Chemotherapy with or without radiation therapy in limited small-cell carcinoma of the lung. N Engl J Med 1987; 316: 912-918.

4. Turrisi AT, Kim K, Blum R, Sause WT, Livingston RB, Komaki R, Wagner H, Aisner S, Johnson DH. Twice-daily compared with once-daily thoracic radiotherapy in limited small-cell lung cancer treated concurrently with cisplatin and etoposide. N Engl J Med 1999; 340: 265-271. 
5. Takada M, Fukuoka M, Kawahara M, Sugiura T, Yokoyama A, Yokota S. Phase III study of concurrent versus sequential thoracic radiotherapy in combination with cisplatin and etoposide for limited-stage small-cell lung cancer: results of the Japan Clinical Oncology Group Study 9104. J Clin Oncol 2002; 20: 3054-3060.

6. Skarlos DV, Samantas E, Briassoulis E, Panoussaki E, Pavlidis N, Kalofonos HP. Randomized comparison of early versus late hyperfractionated thoracic irradiation concurrently with chemotherapy in limited disease smallcell lung cancer: a randomized phase II study of the Hellenic Cooperative Oncology Group (HeCOG). Ann Oncol 2001; 12: 1231-1238.

7. Baas P, Belderbos JS, Senan S, Kwa HB, van Bochove A, van Tinteren H. Concurrent chemotherapy (carboplatin, paclitaxel, etoposide) and involved-field radiotherapy in limited stage small cell lung cancer: a Dutch multicenter phase II study. Br J Cancer 2006; 94: 625-630.

8. Schild SE, Bonner JA, Hillman S, Kozelsky TF, Vigliotti AP, Marks RS. Results of a phase II study of high-dose thoracic radiation therapy with concurrent cisplatin and etoposide in limited-stage small-cell lung cancer (NCCTG 95-20-53). J Clin Oncol 2007; 25: 3124-3129.

9. van Loon J, Offermann C, Bosmans G, Wanders R, Dekker A, Borger J. 18FDG-PET based radiation planning of mediastinal lymph nodes in limited disease small cell lung cancer changes radiotherapy fields: a planning study. Radiother Oncol 2008; 87: 49-54.

10. Watkins JM, Wahlquist AE, Zauls AJ, Shirai K, GarrettMayer E, Aguero EG. Involved-field radiotherapy with concurrent chemotherapy for limited-stage small-cell lung cancer: disease control, patterns of failure and survival. J Med Imaging Radiat Oncol 2010; 54: 483-489.

11. Hu X, Bao Y, Zhang L, Guo Y, Chen YY, Li KX. Omitting elective nodal irradiation and irradiating postinduction versus preinduction chemotherapy tumor extent for limitedstage small cell lung cancer: interim analysis of a prospective randomized noninferiority trial. Cancer 2012; 118: 278-287.

12. De Ruysscher D, Bremer RH, Koppe F, Wanders S, van Haren E, Hochstenbag M. Omission of elective node irradiation on basis of CT-scans in patients with limited disease small cell lung cancer: a phase II trial. Radiother Oncol 2006; 80: 307-312.

13. van Loon J, De Ruysscher D, Wanders R, Boersma L, Simons J, Oellers M. Selective nodal irradiation on basis of (18)FDG-PET scans in limited-disease small-cell lung cancer: a prospective study. Int J Radiat Oncol Biol Phys 2010; 77: 329-336.

14. Warren LE, Miller CL, Horick N, Skolny MN, Jammallo LS, Sadek BT. The impact of radiation therapy on the risk of lymphedema after treatment for breast cancer: a prospective cohort study. Int J Radiat Oncol Biol Phys 2014; 88: 565-571.

15. Xia B, Chen GY, Cai XW, Zhao JD, Yang HJ, Fan M. Is involved-field radiotherapy based on $\mathrm{CT}$ safe for patients with limited-stage small-cell lung cancer. Radiother Oncol 2012; 102: 258-262.

16. Som PM, Curtin HD, Mancuso AA. An imaging-based classification for the cervical nodes designed as an adjunct to recent clinically based nodal classifications. Arch Otolaryngol Head Neck Surg 1999; 125: 388-396.

17. Feng ZX, Zhao LJ, Guan Y, Sun Y, Meng MB, Ji K, Wang P. Identification of risk factors and characteristics of supraclavicular lymph node metastasis in patients with small cell lung cancer. Med Oncol 2013; 30: 493.

18. Xing J, Luo Y, Wang X, Gao M, Sun M, Ding X. Anatomic distribution of supraclavicular lymph node in patients with esophageal cancer. Onco Targets Ther 2016; 9: 5803-5808.

19. Brown LC, Diehn FE, Boughey JC, Childs SK, Park SS, Yan ES. Delineation of supraclavicular target volumes in breast cancer radiation therapy. Int J Radiat Oncol Biol Phys 2015; 92: 642-649.

20. van den Brekel MW, Stel HV, Castelijns JA, Nauta JJ, van der Waal I, Valk J. Cervical lymph node metastasis: assessment of radiologic criteria. Radiology 1990; 177: 379-84.

21. Jing H, Wang SL, Li J, Xue M, Xiong ZK, Jin J. Mapping patterns of ipsilateral supraclavicular nodal metastases in breast cancer: rethinking the clinical target volume for high-risk patients. Int J Radiat Oncol Biol Phys 2015; 93: 268-276.

22. Luo Y, Liu Y, Wang X, Zhang B, Yu J, Wang C. Mapping patterns of nodal metastases in esophageal carcinoma: rethinking the clinical target volume for supraclavicular nodal irradiation. J Thorac Dis 2016; 8: 3132-3138.

23. Bogart JA, Herndon JE, Lyss AP, Watson D, Miller AA, Lee ME. 70 Gy thoracic radiotherapy is feasible concurrent with chemotherapy for limited-stage small-cell lung cancer: analysis of Cancer and Leukemia Group B study 39808. Int J Radiat Oncol Biol Phys 2004; 59: 460-468.

24. Videtic GM, Belderbos JS, Spring KFM, Kepka L, Martel MK, Jeremic B. Report from the International Atomic Energy Agency (IAEA) consultants meeting on elective nodal irradiation in lung cancer: small-cell lung cancer (SCLC). Int J Radiat Oncol Biol Phys 2008; 72: 327-334.

25. Tada T, Minakuchi K, Koda M, Masuda N, Matsui K, Kawase I, Nakajima T, Nishioka M, Fukuoka M, Kozuka T. Limited-stage small cell lung cancer: local failure after chemotherapy and radiation therapy. Radiology 1998; 208: 511-515.

26. Graham P, Jagavkar R, Browne L. Supraclavicular radiotherapy must be limited laterally by the coracoid to avoid significant adjuvant breast nodal radiotherapy lymphoedema risk. Australas Radiol 2006; 50: 578-582.

27. Whelan TJ, Olivotto IA, Parulekar WR, Ackerman I, Chua BH, Nabid A, Vallis KA, White JR, Rousseau P, Fortin A, Pierce LJ, Manchul L, Chafe S, Nolan MC, Craighead P, Bowen J, McCready DR, Pritchard KI, Gelmon K, Murray Y, Chapman JA, Chen BE, Levine MN; MA20 Study Investigators. Regional Nodal Irradiation in Early-Stage Breast Cancer. N Engl J Med 2015; 373: 307-316. 
28. Luo Y, Wang X, Liu Y, Wang C, Huang Y, Yu J. Identification of risk factors and the pattern of lower cervical lymph node metastasis in esophageal cancer: implications for radiotherapy target delineation. Oncotarget 2017.

29. Bradley JD, Dehdashti F, Mintun MA, Govindan R, Trinkaus K, Siegel BA. Positron emission tomography in limited-stage small-cell lung cancer: a prospective study. J Clin Oncol 2004; 22: 3248-3254.

30. Choi HJ, Ju W, Myung SK, Kim Y. Diagnostic performance of computer tomography, magnetic resonance imaging, and positron emission tomography or positron emission tomography/computer tomography for detection of metastatic lymph nodes in patients with cervical cancer: meta-analysis. Cancer Sci 2010; 101: 1471-1479.

\section{*Correspondence to}

Yan Dang

Department of Respiratory Medicine

Xianyang Center Hospital

PR China 